\title{
Unilateral Ureterocele Presenting With Multiple Stones In An Old Lady: Endoscopic Incision and Stone Extraction
}

\author{
Mehmet Bilgehan Yuksel ${ }^{1 *}$
}

\begin{abstract}
In this video included case presentation, we aimed to present the application of endoscopic incision of ureterocele and simultaneous stone extraction in an old female with a large ureretocele containing multiple urinary stones and to show the affectivity and applicability of endoscopic treatment of ureterocele in elderly patients.
\end{abstract}

Key words: Ureterocele, Duplex Collecting System, Endoscopic Incision, Adult, Stone Extraction

\section{Introduction}

Ureterocele is commonly unilateral and intravesical disorder in adults (1). The overall incidence of stones in ureterocele varies from $\% 4$ to $\% 39$. The dysfunction of ureteral motility and urinary stasis provoke the formation of subsequent urinary stone in ureterocele. Thus, ureterocele is commonly concomitant with urinary stone disease $(2$, 3).

Various treatment alternatives are present for the treatment of ureterocele. Although controversies are present regarding the effectiveness of endoscopic incision, the studies have shown that the risk of iatrogenic vesicoureteral reflux is commonly low if a low transverse incision was performed $(4,5)$.

Furthermore, endoscopic ureterocele incision and stone extraction is an effective and minimally invasive treatment alternative for adult ureterocele containing concomitant urinary stone with minimal risk of iatrogenic vesicoureteral reflux and other complications related to the surgery (6).

Case

In this video, we aimed to present our step-bystep technique of endoscopic incision of ureterocele and stone extraction in a 66 years old female patient with an extremely big ureterocele containing multiple urinary stones.

The patient was with the complaints of flank pain and disuria. Preoperative intravenous pyelography (IVP) revealed a right complete duplicated renal collecting system, severe dilatation and tortuosity of upper pole ureter, an extremely big ureterocele at the end of the upper pole ureter and multiple urinary stones inside the ureter and ureterocele. She has the history of previous appendectomy and the comorbidities of hypertension and coronary artery disease. The patient was diagnosed ureterocele with multiple urinary stones and an endoscopic treatment was planned.

The patient was prepared under spinal anaesthesia and positioned in lithotomy position. Under direct visualisation of cystoscopic view, the ureterocele and other ureteral orifice of the duplicated urinary system have been detected.

A ureteral catheter was placed into the other ureter for safety. Subsequently, a transverse endoscopic incision was performed by using a $26 \mathrm{~F}$ standard resectoscope with an electrical loop of transurethral incision of prostate (TUIP) at the inferior border, and an artificial secondary ureteral orifice has been created.

Through this new orifice, the resectoscope was inserted into the ureter, and multiple ureteral stones were seen inside the ureterocele cavity and dilated ureter. These stones were extracted by using stone forceps and directly irrigation and decompression of the ureteral lumen. No stone fragmentation was required in this operation. After the elimination of all of the stones, a $4.8 \mathrm{~F}$ DJ stent was inserted into the ureter and the procedure has been completed without any complications

(http://medscidiscovery.com/?msd=Videos).

At the postoperative follow up period, no complication was occurred and all of the complaints were improved. Postoperative 6th month IVP showed that severe hydronephrosis and ureteral tortuosity at preoperative IVP was significantly improved. 


\section{Conclusion}

This video included case presentation revealed that ureterocele incision should be safely used for the treatment of ureterocele in adults. In addition, additional interventions for concomitant disorders, such as urinary stone, can be simultaneously applied without any requirements of other surgical interventions.

\section{References}

Schlussel RN, Retik AB. Ectopic ureter, ureterocele and other anomalies of the ureter. In: Wein AJ, Kavoussi LR, Novick AC, et al, eds. Campbell-Walsh urology. 9th ed. Philadelphia: Saunders; 2007:3383-3422.

Nash AG, Knight M. Ureterocele calculi. Br J Urol. 1973;45:404 407.

Lieb J, Abrahams HM, Das AK. Endoscopic management of milk of calcium-filled ureterocele stump. J Endourol. 2003;17:917-918.

Tortora FL Jr, Landes R. Endoscopic ureteroneocystostomy for orthotopic ureteroceles. J Urol. 1982;127:31-33.

Rich MA, Keating MA, Snyder HM III, et al. Low transurethral incision of single system intravesical ureteroceles in children. $J$ Urol. 1990;144:120-121

Shah HN, Sodha H, Khandkar AA, et al. Endoscopic management of adult orthotopic ureterocele and associated calculi with holmium laser: experience with 16 patients over 4 years and review of literature. J Endourol. 2008;22:489-495.

Copyright (C) 2014 The Author(s); This is an open-access article distributed under the terms of the Creative Commons Attribution License (http://creativecommons.org/licenses/by/4.0), which permits unrestricted use, distribution, and reproduction in any medium, provided the original work is properly cited. 